\title{
International Mobility, Joint Working and European Research
}

\author{
ALEX N. HALLIDAY* and LAURA WILTON** \\ *The Earth Institute, Columbia University, 104 Hogan Hall, 2910 Broadway, \\ New York, NY 10025, USA. Email: AlexHalliday@ei.columbia.edu \\ **The Royal Society, 6-9 Carlton House Terrace, London SW1Y 5AG, UK. \\ Email: laura.wilton@royalsociety.org
}

\begin{abstract}
A discussion of the sustainability and resilience of European research could not come at a more opportune and important time, as the EU begins to shape its new research programme Horizon Europe, and the UK considers the future following its vote to leave the European Union. Faced with such disruption, we must establish goals and make plans to develop a stronger European research endeavour. Since the UK's vote to leave the European Union in June 2016, representatives of the UK's national academy of science, the Royal Society, have travelled extensively to underline the global nature of science. We have found supportive partners, willing to work together towards a good outcome for European research. In addition, we have been involved in close discussions with the UK Government.
\end{abstract}

The Royal Society has focused on three areas where we think we will see the main impact of Brexit, the UK leaving the EU, on international research:

(1) Mobility and collaboration;

(2) Funding and infrastructures;

(3) Regulation and policy.

The first of these, mobility and collaboration, arguably is the most important and is critical for the future of the European research enterprise. ${ }^{1}$

\section{Mobility}

Primarily, research is a personal, inquisitive enterprise. Whether an astronomer or an historian, one's prime motivation is the sense of fascination and energy derived from interesting observations and the need to figure something out. It is creative and 
individualistic, but it fuels discovery and can lead to societal transformation on the scale of the European industrial revolution.

In reality, it was not just individuals that fuelled the industrial revolution. It had become clear in the 1500 s and 1600 s that research benefited from discussion, collaboration and mobility, even on an international scale. This led to the founding of the Royal Society and other national and regional academies across Europe. They did not just talk in an academic environment. Researchers also travelled to discuss ideas or to conduct experiments. Mobility was so important that European academies such as the Royal Society established positions like that of Foreign Secretary, in the early 1700s.

Even during times of political instability, international exchange of research findings was hugely important to Europe. For example, Humphry Davy travelled to Paris to accept an award from Napoleon despite the fact that Britain and France were at war at the time. The power of science to transcend international politics and the recognised benefits for all that it brings is also true today. In May 2017 we saw the opening of Synchrotron-Light for Experimental Science and Applications in the Middle East (SESAME) - a synchrotron facility for scientists from across the Middle East, based in Jordan, but also funded by Bahrain, Cyprus, Egypt, Iran, Israel, Pakistan, the Palestinian Authority and Turkey. ${ }^{2}$

The international nature of research is widely recognised by scientists, used to travelling and working abroad to gain experience and contribute to the most exciting endeavours, some of them necessitating large-scale collaboration. The Twitter hashtag 'Science is Global' that followed the Brexit vote is not just a voice of community support around the world; it is a statement of how research has to work in order to be most successful, regardless of political turmoil. ${ }^{3}$ When people move between countries for research, they take their skills and expertise with them, building new networks but retaining lasting links. When people share resources, everybody benefits from access to better facilities at a cheaper price as well as from sharing in bigger discoveries.

So working together across Europe is crucial for achieving the best research for everybody. Over time, the attitude to funding science in Europe has changed for the better, thanks, in part, to the EU. Better funding for top research and researchers and globally competitive shared facilities has enabled many countries to support talent, and attract back many who had gone elsewhere, notably to the USA. Furthermore, excellent pan-European learned societies and academies such as Academia Europaea now exist.

This attitude to science funding benefits countries such as the UK, which has been a huge beneficiary of working within Europe. Research by the Royal Society has shown that $72 \%$ of active UK researchers have trained or worked as researchers abroad. The most common destination for researchers from the UK is of course the USA, but Germany and France are second and third. The UK has been successful in securing European Union grants, and during the previous EU research programme, FP7, UK institutions attracted a quarter of all Marie Curie Fellows. Over half of the UK's research publications in 2015 were the result of international collaboration, $60 \%$ of which included EU partners, and this percentage is increasing at a fast rate. ${ }^{4}$ 


\section{Brexit}

For these and other reasons, Brexit is viewed as a serious threat to research by colleagues and organisations across Europe. Many European countries benefit from the UK's strength in research and have expressed their concern for how Brexit will impact European research as a whole. We need urgently to define a big vision and organisational structure for European research that will thrive - despite Brexit. In fact, this is a good time to define a vision as policy-makers are becoming increasingly aware of the importance of science. One of UK Prime Minister Theresa May's 12 priorities for the Brexit negotiations is science and innovation. ${ }^{5}$ In his State of the Union conference speech in Florence, European Commission Chief Negotiator Michel Barnier cited research and higher education policy, noting 'how important EU policy is for creating networks and exchanges between universities in all 28 countries'. ${ }^{6}$ In September 2017, the UK Government outlined positive proposals for supporting research across the EU, post-Brexit.

We must grasp this opportunity to discuss and propose the best outcome for European research from these negotiations. Charles de Gaulle, speaking in Strasbourg in 1959, said, 'Yes, it is Europe, from the Atlantic to the Urals, it is Europe, it is the whole of Europe that will decide the fate of the world' ${ }^{7}$ We need this pan-European view of research more than ever. We also need fresh and strategic panEuropean thinking about the research areas in which we want Europe to be a world leader.

\section{Planning a Future of European Research}

Europe has an outstanding record of accomplishment in research. It is also brilliant at highly skilled manufacturing. These provide Europe with major advantages.

There are reasons why so many leading car manufacturers are based in Europe and why so much Formula 1 technology is developed there. NASA chooses to commission European countries to help build kit for its space missions, including the James Webb Space Telescope - the successor to Hubble. Europe is the home of recent discoveries such as the Higgs boson. The world's biggest fusion projects are based in Europe. There are reasons why the most accurate predictor of tropical storms globally, the European Centre for Medium-Range Weather Forecasts (ECMWF), is based in Europe. It is to do with a widely accepted respect for education, knowledge, science and technology, ambitious collaborative thinking and the creation of worldleading shared facilities.

Leading institutions and scientific organisations, such as the Max Planck Society, regularly take decisions to shape the areas of research in which they want to grow and excel. We, as a wider European research community, might want to do the same thing. A number of questions can be posed as a way of shaping a strategic vision for European research. 
(1) In what areas of research does Europe really want to excel?

(2) What aspects of European culture, creativity, facilities, research strength and mobility provide us with particular advantages?

(3) What are the global societal challenges, such as climate change, where working together will help internationally?

(4) What are the barriers to collaboration and the perverse incentives that need addressing?

(5) What are the most nimble and responsive structures for catalysing novel forms of joint working?

(6) How can we use research and research training to strengthen individual European countries?

(7) Finally, what new European-scale infrastructure needs consideration?

We might benefit from a strategic approach to identifying the different research strengths across European countries. The UK has only really done this systematically in a small way so far. We should be bold and think about how we work together on machine learning, energy storage, cybersecurity, autonomous vehicles, biomedical engineering, data governance, the future of the oceans, quantum technologies and the Internet of Things.

This means working collectively, which is something that Europe can be good at, but not always. European nations recognised the value of pooling resources to create the European Space Agency. It has been a great success. However, it is important that politics does not interfere in decision-making and that the benefits to individual countries are seen as stemming from joint efforts to produce the best mission, not from the mission that provides the most resources to any one country. Sometimes these attitudes undermine the quality of what can and should be achieved by European researchers and technologists. Our competition is no longer with each other; it is with the burgeoning powerhouses of technology elsewhere in the world.

We should also be ambitious, because we operate in a highly competitive marketplace. The report by the High Level Group on maximising investment in European research, chaired by Pascal Lamy, advocated doubling the budget for Horizon Europe and, crucially, recognised that is was both in the interest of the UK and the EU to work together on research in the future. ${ }^{8}$

We must build upon our European strength to provide a strong knowledge-based economy with large markets in the future. With disruptive technologies developing, what major role will Europe have when it is politically divided into medium and small countries speaking different languages and with different rules? Greater integration and harmonisation will be required to compete with the scale of the market opportunity in the US and China. We need to ensure that Europe does not become 'a nation of shopkeepers"9 (as Napoleon called Britain), with an economy dominated by retail and service industries.

We also have to find ways of better connecting our academic research and innovation with the needs of ordinary citizens. Despite all of the concerns raised preBrexit by the Royal Society and others about the future of research, it did not seem to 
matter that much to most UK citizens when they had to vote. We might want to reflect on why research is not seen as more crucial. UK citizens are becoming aware that, for the first time in a while, their children will be worse off than they are. What can research offer to address this? We need to make our research relevant in terms of new jobs, better lives, stronger communities and improved healthcare. This is a European issue as much as a global one.

We must focus on being creative, energetic and ambitious about future joint working at a time of change. Former US President Bill Clinton once said 'The urgent question of our time is whether we can make change our friend and not our enemy. ${ }^{10}$ We need to embrace change as our friend over the coming years.

\section{Acknowledgement}

Adapted from a speech given at the ALLEA-AE Joint Conference on 6 September 2017 in Budapest, Hungary, by Alex N. Halliday. To find out more about the Royal Society's work on Brexit and UK science, please see: https://royalsociety.org/topicspolicy/projects/brexit-uk-science/

\section{References}

1. For information on the Royal Society's work on Brexit and UK science, see https://royalsociety.org/topics-policy/projects/brexit-uk-science/ (accessed 26 January 2018).

2. http://www.sesame.org.jo/sesame/ (accessed 26 January 2018).

3. For more information on the Science is Global campaign, see: https:// royalsociety.org/topics-policy/publications/2016/european-academies-statement-science-is-global/ (accessed 26 January 2018).

4. https://royalsociety.org/topics-policy/projects/international-researcher-mobility/ (accessed 26 January 2018).

5. UK Government (2018) The government's negotiating objectives for exiting the EU: PM speech. See https://www.gov.uk/government/speeches/the-governments-negotiating-objectives-for-exiting-the-eu-pm-speech (accessed 26 January 2018).

6. European Commission (2017) Speech by Michel Barnier at the Seventh State of the Union Conference. European University Institute, Florence, http://europa. eu/rapid/press-release_SPEECH-17-1236_en.htm (accessed 31 January 2018).

7. E. Knowles (Ed) (1999) The Oxford Dictionary of Quotations (New York: Oxford University Press), p. 255.

8. Report of the Independent High Level Group on Maximising the Impact of EU Research \& Innovation Programmes (2017) LAB-FAB-APP Investing in the European future we want, see http://ec.europa.eu/research/evaluations/pdf/ archive/other_reports_studies_and_documents/hlg_2017_report.pdf\#view= fit\&pagemode=none, p. 21 (accessed 26 January 2018).

9. E. Knowles (Ed) (1999) The Oxford Dictionary of Quotations (New York: Oxford University Press), p. 539.

10. New York Times (1993) The Inauguration. 'We Force the Spring': Transcript of Address by President Clinton, http://www.nytimes.com/1993/01/21/us/theinauguration-we-force-the-spring-transcript-of-address-by-president-clinton. html?pagewanted=all (accessed 26 January 2018). 


\section{About the Authors}

Alex N. Halliday is Director of the Earth Institute at Columbia University in New York. He was formerly Professor of Geochemistry and Head of the Science and Engineering Division at Oxford University, and Physical Secretary and Vice-President of the Royal Society. Before coming to Oxford, he spent 12 years as a professor at the University of Michigan and then six years in Switzerland, where he was Head of the Department of Earth Sciences at the ETH in Zürich. An enthusiast for technological innovation, most of Halliday's recent research is in developing and using mass spectrometry techniques to shed light on the origin and early development of the solar system and recent Earth processes, such as continental erosion and climate. However, he has also been engaged in other studies, such as in understanding mantle processes, volcanic systems, and the formation of mineral deposits. Halliday is a former President of the Geochemical Society, the European Association of Geochemistry, and the Volcanology, Geochemistry and Petrology Section of the American Geophysical Union. Halliday's scientific accomplishments have been recognised with awards including the Murchison Medal of the Geological Society, the Bowen Award and Hess Medal of the American Geophysical Union, the Urey Medal of the European Association of Geochemistry and the Oxburgh Medal of the Institute of Measurement and Control. He was elected a Fellow of the Royal Society in 2000, is a Member of Academia Europaea and is a Foreign Associate of the US National Academy of Sciences.

Laura Wilton is Head of International Affairs - Europe and Asia at the Royal Society, the National Academy of science in the UK. In her role at the Society she has oversight of international relations with Europe and Asia, where she has used her extensive experience of the European Union and European politics. She has previously worked at Policy Connect, Westminster Parliamentary Research and Chatham House, the Royal Institute of International Affairs. She has a background in history and international relations from King's College London. 